\title{
RESENHA
}

http://dx.doi.org/10.1590/So034-759020140512

\section{UM NOVO CRITÉRIO DE ESTRATIFICAÇÃO SOCIAL E DE CONSUMO}

\section{ESTRATIFICAÇÃO SOCIECONÔMICA E CONSUMO NO BRASIL}

De Wagner A. Kamakura; José Afonso Mazzon. São Paulo: Editora Blucher, 2013. 286 páginas.

Há muito tempo, o conceito de classe social tem sido utilizado em marketing. A mensuração de classe social e de status socioeconômico tem desempenhado um papel importante em pesquisas de segmentação de mercado. Para o marketing, o conceito de status socioeconômico define a posição de um indivíduo ou de uma família dentro de um sistema estratificado social, revelando o contexto em que ocorre o consumo de bens e serviços. Esse conceito vem ganhando ainda mais importância, dados o crescimento e tamanho dos mercados dos países que compõem os Brics e, em especial, pela emergência de uma classe média com poder de compra mais elevado.

É com o objetivo de contribuir com um melhor entendimento desse perfil da população e, assim, fornecer mais base para a segmentação de mercado e pesquisas de marketing que Wagner A. Kamakura e José Afonso Mazzon desenvolveram o livro Estratificação socieconômica e consumo no Brasil. Nesta obra, os autores buscam identificar novos estratos socioeconômicos na sociedade brasileira, além de analisar o comportamento do consumidor em cada estrato, em termos de consumo e prioridades.

José Afonso Mazzon, embora tenha o background das Ciências Econômicas, seguiu a carreira acadêmica na área de administração. 0 foco de seus estudos é Modelagem de Comportamento do Consumidor e Marketing Social, experiências que lhe forneceram condições para elaborar esta publicação. Wagner A. Kamakura é professor de marketing no Texas (EUA), e leciona também em outras universidades ao redor do mundo. Sua atuação nas áreas de marketing de empresas brasileiras, bem como o início da vida acadêmica no Brasil, o credencia para abordar o tema do livro.

A principal inovação no modelo é a inclusão do conceito de renda permanente. Até

Franklin de Souza Meirelles franklinmeirelles@gmail.com Mestrando em Marketing Internacional pelo Programa de Mestrado e Doutorado em Gestão Internacional, Escola Superior de Propaganda e Marketing - São Paulo - SP, Brasil

Renata Pozelli Sabio renatapozelli@hotmail.com Mestrando em Marketing Internacional pelo Programa de Mestrado e Doutorado em Gestão Internacional, Escola Superior de Propaganda e Marketing - São Paulo - SP, Brasil então, o critério de classificação socioeconômico brasileiro utilizava apenas o conceito de renda corrente em sua estratificação. Os autores demonstram, ainda, que a renda corrente é um indicador importante e necessário na composição do status socioeconômico, mas que esse indicador por si só não é suficiente. Nesse sentido, os autores citam Duncan et al., (Optimal indicators of socioeconomic status for health research, American Journal of Public Health, 2002) e Friedman (A theory of the consumption function, Princeton: Princeton University, 1975), que defendem o uso da renda permanente. Segundo os autores, a renda corrente é um indicador fraco do padrão de vida, pois não reflete os recursos financeiros disponíveis, como o acesso a crédito e investimentos. Além disso, o comportamento de consumo é determinado principalmente pela renda perma- 
nente e, assim, o consumo correlaciona-se mal com a renda corrente. Portanto, segundo os autores, o status socioeconômico deve ser inferido a partir de indicadores que revelam a capacidade do indivíduo de se mover ou permanecer no estado atual e sua capacidade para tirar proveito dos recursos da sociedade.

A fim de contextualizar e justificar a importância da estratificação, os autores apresentam a evolução do conceito de classe social desde a antiguidade até os dias atuais. O capítulo intitulado "Classes sociais e estratos socioeconômicos" mostra os diversos critérios de estratificação utilizados em diferentes países, dando ênfase à estratificação socioeconômica atualmente usada no Brasil.

Em seguida, abordam a metodologia para as definições socioeconômicas, destacando as diferenças com o modelo atual. No modelo proposto, não há dependência de critérios subjetivos por parte do pesquisador, como ocorre com o Critério de Classificação Econômica Brasil. Além disso, possibilita a incorporação de variáveis que diferenciam a estratificação socioeconômica baseada em renda permanente e status social, como composição familiar, região geográfica e tipo de município em que se localiza uma residência.

O Critério de Classificação Econômica Brasil foi desenvolvido como um previsor de renda corrente e baseado na renda declarada e não comprovada. Já o modelo proposto na obra é baseado nos dados da Pesquisa de Orçamentos Familiares (POF), portanto utiliza dados de renda corrente comprovada. A escolha da POF deve-se ao fato de que esta reflete o conceito de comprobabilidade, ao contrário da Pesquisa Nacional por Amostra de Domicílios (PNAD), na qual as informações obtidas são de natureza declarada pelos respondentes.

Primeiramente, os autores fizeram a identificação de estratos socioeconômicos chamados de "naturais" na socie- dade brasileira por meio do modelo de classes latentes. Essa metodologia tem vantagens sobre outros métodos utilizados para a estratificação socioeconômica, pois permite a identificação de classes que ocorrem naturalmente nos dados observados. Como desvantagens, tem caráter conceitual e operacionalmente complexo, e a atualização da estrutura de classes socioeconômicas com dados mais recentes requerer o desenvolvimento e a estimação de um novo modelo.

No capítulo "Classes socioeconômicas e consumo no Brasil", os autores discutem os níveis de consumo obtidos nas classes socioeconômicas apresentadas anteriormente, além de sugestões de como as empresas podem beneficiar-se dessa classificação para definir suas estratégias de marketing. Esse capítulo pode ser considerado o de maior relevância do livro, pois é nele que todos os conceitos e métricas abordados até então são ilustrados na prática, a fim de que o leitor consiga entender a utilidade do novo modelo proposto não apenas para a academia, mas para diversos setores privados.

Os autores apresentam os resultados do perfil do consumidor brasileiro em cada um dos sete estratos para os $21 \mathrm{ti}$ pos de produtos abordados na POF e detalhados no capítulo três. O clímax do livro, porém, é o capítulo quatro, pois, além de ilustrar os resultados da segmentação dentro dos estratos, mostra a utilidade da segmentação proposta para instituições públicas e também pelas organizações privadas.

Em seguida, é apresentado um estudo na cidade de São Paulo buscando identificar outras características que não apenas de consumo, mas também valores, atividades, interesses. 0 recorte para a cidade de São Paulo é aparentemente feito por questões de facilitação metodológica, além de ser uma exemplificação para que o leitor aplique o modelo em outras amostras.
No capítulo seis, são apresentados instrumentos de classificação que podem ser utilizados por pesquisadores para obter a estratificação de suas amostras, o que também é um dos pontos positivos da proposta dos autores. Os modelos diferenciam-se de acordo com a condição da coleta dos dados, ou seja, apresentam maneiras de se obterem os dados finais mesmo com ausência de informações previstas no modelo e com condições precárias de coleta.

Acreditamos que o mesmo estudo realizado em São Paulo pode apresentar resultados diferentes quando realizado em outras regiões do País, diferenças essas não relacionadas ao comportamento dentro dos estratos, mas em relação ao comportamento geral da população estudada, por conta de diferenças econômicas e culturais da população brasileira.

A obra contribui para o preenchimento de gaps existentes no modelo de estratificação até então vigente no País, em especial a não consideração da região geográfica. Além disso, o detalhamento do grau de consumo por tipos de produtos, por si só, já representa informações de extrema relevância para os setores público e privado.

Embora a utilização de dados da POF, bem como o desenvolvimento a partir de cálculos avançados, dê credibilidade ao modelo, a complexidade de execução e replicação do estudo, somada à necessidade constante de ajustes dos dados, principalmente com a mudança nas condições econômicas e sociais no Brasil, limita o seu uso em pesquisas nas quais o orçamento e o tempo disponível são escassos. Além disso, como a última POF foi publicada em 2008/09, e a próxima ainda não tem data prevista para publicação, a estratificação feita pelos autores pode estar ou ficar desatualizada, devido às recentes mudanças que vêm ocorrendo na distribuição de renda dos brasileiros. 